\title{
Role of culturally protected forests in biodiversity conservation in Southeast China
}

\author{
Hong Gao $\cdot$ Zhiyun Ouyang $\cdot$ Shengbin Chen $\cdot$ C. S. A. van Koppen
}

Received: 23 November 2011/Accepted: 14 December 2012/Published online: 3 January 2013

(C) Springer Science+Business Media Dordrecht 2012

\begin{abstract}
Culturally protected forests (CPFs), preserved and managed by local people on the basis of traditional practices and beliefs, have both social and ecological functions. We investigated plant species richness and diversity within the tree layer, shrub layer and herb layer in three types of CPFs (community forests, ancestral temple forests, cemetery forests) as well as nearby forests without cultural protection (NCPFs) in Southeast China. A total of 325 species belonging to 85 families and 187 genera were recorded in CPFs, including 17 protected species in China Species Red List and IUCN Red List, which accounted for $17 \%$ of counties' endangered species. Compared with NCPFs, the tree layer of CPFs had larger DBH and lower species density, especially in the cemetery forests. CPFs had higher alpha diversity values generally, particularly in the tree layer. The differences in tree layer were substantial, and CPFs covered nearly $85.4 \%$ of the tree species in the surveyed sites. The similarities between CPFs and NCPFs were higher in the herb and shrub layers than in the tree layer. These differences of species diversity may be attributed to differences in resource use and management between CPFs and NCPFs. Our field investigation results suggested that local CPFs harbor many plant species, high biodiversity, and contribute to the conservation of a substantial proportion of the local species pool.
\end{abstract}

Keywords Culturally protected forests - Community structure $\cdot$ Species composition · Species diversity $\cdot$ Southeast China

Electronic supplementary material The online version of this article (doi:10.1007/s10531-012-0427-7) contains supplementary material, which is available to authorized users.

\footnotetext{
H. Gao $\cdot$ Z. Ouyang $(\bowtie) \cdot$ S. Chen

State Key Laboratory of Urban and Regional Ecology, Research Center for Eco-Environmental Sciences, Chinese Academy of Sciences, Beijing 100085, China

e-mail: zyouyang@rcees.ac.cn

H. Gao

e-mail: gaohong521@gmail.com

C. S. A. van Koppen

Environmental Policy Group, Wageningen University, P.O. Box 8130, 6700, EW,

Wageningen, The Netherlands
} 
In response to the growing threat of biodiversity loss in the world (Pimm et al. 1995; Loreau et al. 2001; Achard et al. 2002), scientists and conservationists are seeking effective ways to improve biodiversity conservation. One of the approaches which has received great attention recently is to acknowledge and include the role of traditional cultural practices and beliefs in protecting and managing biodiversity (Byers et al. 2001; Infield 2001; Fabricius 2004; Berkes and Davidson 2006; Garnett et al. 2007). Culturally protected forests (CPFs), which have been preserved and managed by local communities on the basis of traditional culture, practices and beliefs, have largely been spared from severe deforestation since hunting and deforestation are forbidden. They have usually been preserved and maintained for several decades or even centuries. CPFs are reported to have both social functions and ecological services (Jim 2003; Bhagwat and Rutte 2006; Wassie et al. 2010; Hu et al. 2011). These forests often harbour spiritual, cultural heritage and aesthetic values for local community, and contribute to the local air quality, water provision and micro-climate regulation (Soury et al. 2007; Xu et al. 2009; Yuan and Liu 2009). In recent years, CPFs' management and their role in biodiversity maintenance have been widely discussed, under names such as sacred forests or sacred groves (Jamir and Pandey 2003; Mgumia and Oba 2003; Soury et al. 2007), sacred sites (Salick et al. 2007; Ceperley et al. 2010), fengshui forests (Hu et al. 2011) and church forests (Wassie et al. 2010), particularly in Africa and Asia (Wadley and Colfer 2004; Chun and Tak 2009; Luo et al. 2009; Yuan and Liu 2009; Page et al. 2010).

In traditional Chinese culture, CPFs are widespread, most of them being located besides or around the villages or temples. They can generally be divided into three types: community forests, cemetery forests and temple forests (Guan 2002). Community forests, the most common type of CPFs, are protected by local communities and are reported to play an important role in conserving and regulating the local environment $(\mathrm{Hu}$ et al. 2011). Villagers consider them as a natural shelter around the village, creating a physical barrier between inside and outside, thereby having the function of protection and defense (Zhong and Boris 2007). People bury ancestors, and often hold annual ceremonies in cemetery forests, which were normally managed by large families or clans (Xu et al. 2009). Temple forests are often located around temples, in which sacrificial ceremonies are held on the most important festival occasions in honor of families' ancestors. During the last few years, the CPFs in ethnic minority areas have attracted great interest in China, including the role of holy mountains in protecting species diversity (Ai and Zhou 2003; Yang and Zhao 2004; Xu et al. 2005; Zou et al. 2005; Mo et al. 2011), and the significance of traditional culture and traditional knowledge in managing forest resources in the southwestern ethnic minority area (Long et al. 1999; Fang et al. 2007; Xu 2008). Only a few studies, however, have addressed the issue of CPFs in areas of Southeast China, where the mainstream Han culture prevails (Liu et al. 2002; Liao et al. 2008). This is a caveat, because many CPFs have been protected for long periods under the traditional management of Han people, and almost every village in rural Southeast China has CPFs (Guan 2002; Lü et al. 2008). Furthermore, most of the previous studies have focused on the species composition for one patch or one type of CPF (Cui et al. 2008; Liao et al. 2008), but lack quantitative descriptions and comparisons of community structure and species diversity with the forests that do not have cultural protection (NCPFs).

In this study, we investigated three types of CPFs-community forests, ancestral temple forests and cemetery forests-in five villages in Southeast China. We compared the 
features of the tree, shrub and herb layers with those in NCPFs in the same area to test the differences in community structure, species composition, alpha and beta biodiversity. Based on the field investigation results and information from social surveys in the five villages, we put forward some considerations on the role of cultural protection in the conservation of local biodiversity.

\section{Study area and methods}

Study area

The study was carried out in five villages with traditional Chinese Han culture in Southeast China, two of them in Fujian Province and three in Jiangxi Province (Fig. 1). The climate in the studied region belongs to subtropical humid zone with plentiful sunshine and abundant rainfall. Most of the land is mountainous and the slopes of sample forest plots varied from 5 to 40 degrees (Table 1). The elevation ranged from 87 to $721 \mathrm{~m}$. Zonal vegetation was evergreen broad-leaved forest dominated by Fagaceae, Lauraceae and Theaceae (He et al. 1998; Lan 2003). Longtan, Jiangwan and Fenshui villages are all more than 100 years old with lush community forests which existed for at least the same period. Ancestral temple forests are located in Xibei village, and according to a local forest ranger existed there before the Liao's ancestral temple, which was built in 1848. The cemetery forests in Datang village date from Jiaqing of the Qing Dynasty (1796-1820).

Plots setting and vegetation sampling

The forests were surveyed between May and September 2010. Semi-structured interviews were carried out with key informants about the history, ownership, location and boundaries of the CPFs. Key informants were five venerable old men, six current or former village leaders and one forestry worker. Twelve key informants in total were interviewed, two in each of the villages with community forests, and three in both Datang and Xibei. In this study, we established a total of 50 plots in five different sites for CPFs and NCPFs. Efforts had been made to allocate the plots evenly along the village and to cover most of the distribution area of CPFs and NCPFs. The CPFs were natural forests and ranged from 0.3 to 9 ha in area. The main vegetation was evergreen broad-leaved forest, and appeared to represent almost intact original habitats with limited human disturbance, which is similar to regional climax vegetation (He et al. 1998; Lan 2003). The NCPFs investigated were selected within a range of $1.5 \mathrm{~km}$ from the village. Patch area ranged from 3 to $31 \mathrm{ha}$. In Fenshui, Longtan and Datang villages they were natural secondary forest and in Jiangwan and Xibei villages they were planted forests.

In each village, five plots of $20 \mathrm{~m} \times 20 \mathrm{~m}$ were set within the patches of CPFs or NCPFs. Each plot was evenly divided into four subplots of $10 \mathrm{~m} \times 10 \mathrm{~m}(n=200)$. The minimum distance from the forest edge was $5 \mathrm{~m}$ to avoid edge effects. In the plots, all tree stems with diameter at breast height $(\mathrm{DBH})>3 \mathrm{~cm}$ were identified to species, and $\mathrm{DBH}$ and height were measured. All shrubs (including saplings) were identified within a $5 \mathrm{~m} \times 5 \mathrm{~m}$ sampling area $(n=200)$ in each subplot, and species, number, average crown and height were recorded. Number, species, coverage and height of herbs were also recorded within a sampling area of $1 \mathrm{~m} \times 1 \mathrm{~m}(n=200)$ in each subplot. Plot elevation, 


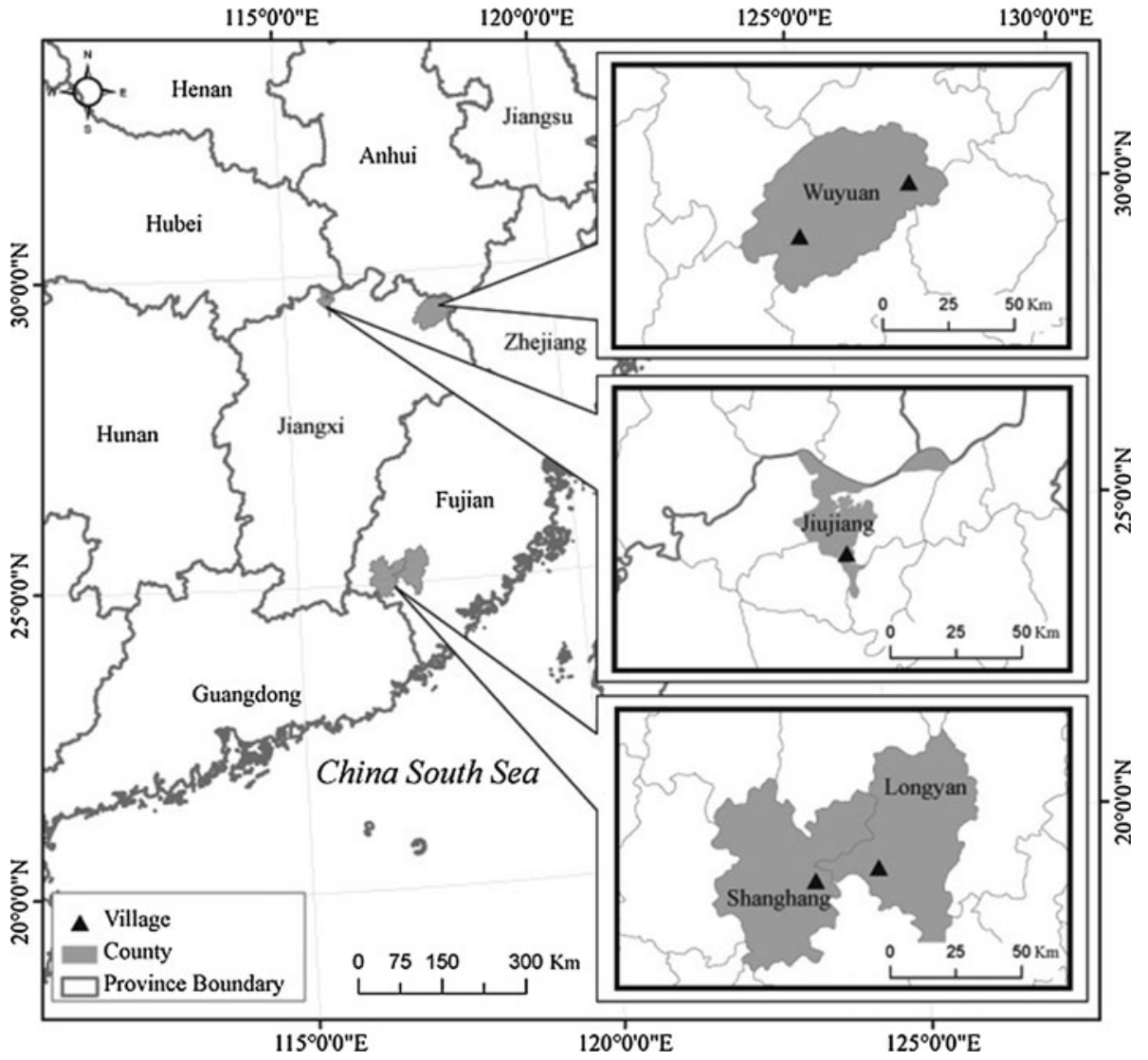

Fig. 1 Locations of the five villages in Southeast China

Table 1 Basic attributes of study area

\begin{tabular}{|c|c|c|c|c|c|}
\hline Village & Location & $\begin{array}{l}\text { Mean annual } \\
\text { temperature }\left({ }^{\circ} \mathrm{C}\right)\end{array}$ & $\begin{array}{l}\text { Mean Annual } \\
\text { precipitation }(\mathrm{mm})\end{array}$ & Altitude (m) & Slope $\left({ }^{\circ}\right)$ \\
\hline Longtan & $\begin{array}{l}\text { N: } 25^{\circ} 06^{\prime} 29^{\prime \prime} \\
\text { E: } 116^{\circ} 55^{\prime} 27^{\prime \prime}\end{array}$ & $18.7-21.0$ & $1031-1369$ & $348-490$ & $15-40$ \\
\hline Xibei & $\begin{array}{l}\text { N: } 25^{\circ} 06^{\prime} 24^{\prime \prime} \\
\text { E: } 116^{\circ} 49^{\prime} 08^{\prime \prime}\end{array}$ & $18.7-21.0$ & $1031-1369$ & $700-721$ & $15-40$ \\
\hline Fenshui & $\begin{array}{l}\text { N: } 29^{\circ} 13^{\prime} 04^{\prime \prime} \\
\text { E: } 117^{\circ} 36^{\prime} 19^{\prime \prime}\end{array}$ & $16.7-18.3$ & $1600-1800$ & $87-130$ & $5-35$ \\
\hline Jiangwan & $\begin{array}{l}\text { N: } 29^{\circ} 22^{\prime} 03^{\prime \prime} \\
\text { E: } 118^{\circ} 03^{\prime \prime} 14^{\prime \prime}\end{array}$ & $16.7-18.3$ & $1600-1800$ & $128-185$ & $8-40$ \\
\hline Datang & $\begin{array}{l}\text { N: } 29^{\circ} 29^{\prime} 29^{\prime \prime} \\
\text { E: } 115^{\circ} 53^{\prime} 41^{\prime \prime \prime}\end{array}$ & $16.0-17.0$ & $1300-1600$ & $135-153$ & $5-10$ \\
\hline
\end{tabular}

slope, aspect, latitude and longitude, and degree of disturbance of sampled forests were also measured. The same vegetation sampling methods were used for both CPFs and NCPFs. 
Data analyses

Importance value

Importance value (IV) was calculated to determine the dominant species (Zhang 2004).

$$
I V_{i}=\left(a_{i}+b_{i}+c_{i}\right) / 3
$$

where $I V_{i}$ represents the importance value of species $I, a$ represents the relative density which equals density of species $i /$ density of all species $\times 100 \%, b$ represents the relative dominance which equals basic area of species $i /$ basic area of all species $\times 100 \%, c$ represents the relative frequency which equals frequency of species $i /$ appearance frequency of all species.

In the above formula, relative dominance values were calculated from cross-sectional area at breast height for trees, crown for shrubs and coverage for herbs.

\section{Species diversity indices}

Species richness $(S)$, Simpson, Shannon-Wiener and Pielou evenness indices were calculated using the following formulas:

Simpson indices: $D=1-\sum_{i=1}^{i} P_{i}^{2}$ (Simpson 1949).

Shannon-Wiener indices: $H_{i}=-\sum_{i=1}^{i} P_{i} \ln P_{i}$ (Shannon and Weaver 1949).

Pielou evenness indices: $J S W=-\sum_{i=1}^{i}\left(P_{i} \ln P_{i}\right) / \ln S$ (Magurran 1988).

where $S$ is species number; $P_{i}=n_{i} / N, n_{i}$ is individual number of species $I, N$ is individual number of all species.

Beta diversity is a key concept for understanding ecosystem functions, biodiversity conservation, and ecosystem management (Legendre et al. 2005). Bray-Curtis index which takes into accounts species abundances was used to measure the similarity between CPFs and NCPFs (Magurran 2005).

The Bray-Curtis index was calculated by EstimateS Win8.20 software (R. K. Colwell, http://purl.oclc.org/estimates). Instead of species abundance, coverage was used to analyze the herb layer. SPSS 18.0 was used to calculate independent sample $t$-tests. Arc GIS 10 and SigmaPlot 11.0 were used to produce the figures.

\section{Results}

Community structure and species composition

\section{Vertical structure}

CPFs had been preserved for a long time, and were generally at the middle to late successional stages. They could be clearly divided into tree layer, shrub layer and herb layer. Tree height and DBH were higher in CPFs than in NCPFs (Fig. 2). In the tree layer, there were two sub-layers; the first was $12-25 \mathrm{~m}$ high with a range of DBH of $30-60 \mathrm{~cm}$. The dominant species were broad-leaved trees, including Castanopsis carlesii, Castanopsis sclerophylla, Tsuga longibracteata, Cinnamomum camphora etc. (Table S1). The second sublayer was 7-12 m high, dominated by Schima superba, Castanopsis fargesii, etc. 


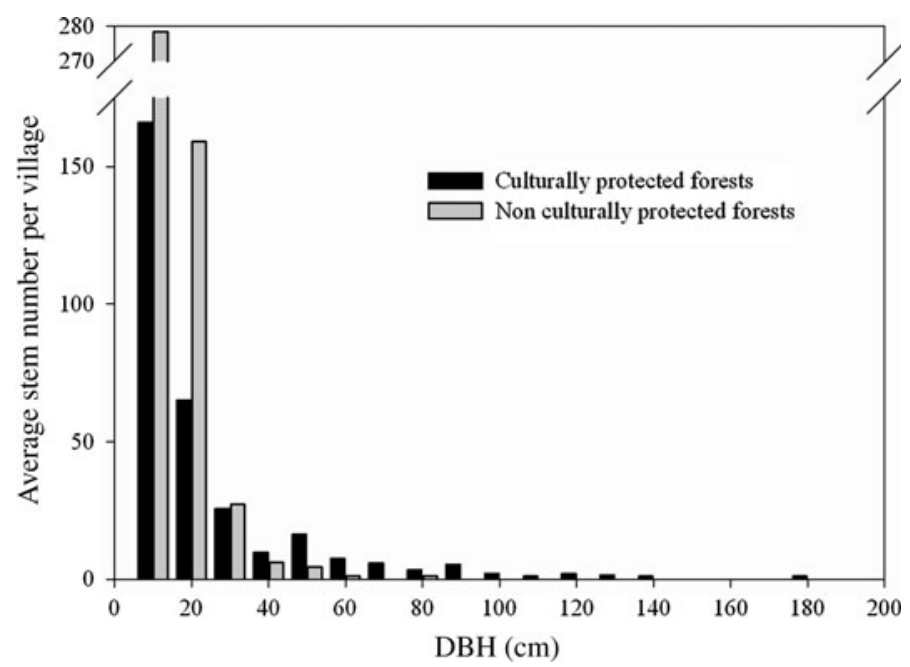

Fig. 2 Average distribution of frequency of $\mathrm{DBH}(\mathrm{cm})$ in $\mathrm{CPFs}$ and NCPFs

NCPFs had only one tree layer with a height range of 6-11 m; the dominant species were Cunninghamia lanceolata, Pinus massoniana and Phyllostachys heterocycla cv. pubescens.

In the shrub layer, the species in CPFs were relatively richer, and were dominated by Eurya muricata, Ardisia japonica, Pleioblastus amarus and Camellia oleifera. The dominant shrub species of NCPFs were Pleioblastus amarus, Camellia sinensis, Adinandra millettii and Loropetalum chinense (Table S1). The difference in the herb layer between CPFs and NCPFs was location-dependent, and the dominant species were Woodwardia japonica, Dryopteris crassirhizoma, and Dicranopteris dichotoma (Table S1).

\section{Species composition}

A total of 325 species belonging to 187 genera and 85 families were found in CPFs while 281 species belonging to 162 genera and 77 families were recorded in NCPFs. The most common families were Fagaceae, Lauraceae, Theaceae and Aquifoliaceae in CPFs, and Fagaceae, Theaceae, Lauraceae and Euphorbiaceae in NCPFs (Table S1). In total, the CPFs had 105 species in the tree layer, 219 species in the shrub layer and 86 species in the herb layer, while the corresponding layers in NCPFs have only 63, 197 and 70 species respectively.

The dominant plant families of the tree layer in community forests CPFs in Longtan, Fenshui and Jiangwan were Lauraceae, Fagaceae, and Theaceae, and the dominant species were Castanopsis sclerophylla and Castanopsis carlesii. In NCPFs, the dominant tree families were Fagaceae, Euphorbiaceae and Theaceae, and the dominant species were Cunninghamia lanceolata and Pinus massoniana (Table S1). In the shrub layer, the most common families were similar in both CPFs and NCPFs, and were the same as the tree layer in CPFs (Table S1). In the herb layer, the most common families were Liliaceae and Dryopteridaceae in CPFs, and Poaceae in NCPFs.

For the ancestral temple forests in Xibei village, the main families of the tree layer were Ericaceae and Fagaceae, and the dominant species was Tsuga longibracteata (Table S1). 
Table 2 Species composition of CPFs and NCPFs

\begin{tabular}{|c|c|c|c|c|c|c|c|}
\hline \multirow[t]{2}{*}{ Site } & \multirow[t]{2}{*}{ Type } & \multicolumn{2}{|c|}{ Tree layer } & \multicolumn{2}{|c|}{ Shrub layer } & \multicolumn{2}{|c|}{ Herb layer } \\
\hline & & CPFs & NCPFs & CPFs & NCPFs & $\mathrm{CPFs}$ & NCPFs \\
\hline \multirow[t]{4}{*}{ Longtan village } & Families & 17 & 15 & 26 & 28 & 15 & 21 \\
\hline & Genera & 26 & 22 & 46 & 49 & 19 & 31 \\
\hline & Species & 33 & 26 & 72 & 68 & 25 & 36 \\
\hline & Density & 0.20 & 0.23 & 0.31 & 0.28 & - & - \\
\hline \multirow[t]{4}{*}{ Fenshui village } & Families & 22 & 19 & 32 & 28 & 10 & 11 \\
\hline & Genera & 34 & 29 & 57 & 47 & 13 & 13 \\
\hline & Species & 48 & 40 & 87 & 72 & 15 & 14 \\
\hline & Density & 0.18 & 0.22 & 0.97 & 1.38 & - & - \\
\hline \multirow[t]{4}{*}{ Jiangwan village } & Families & 23 & 7 & 27 & 24 & 18 & 13 \\
\hline & Genera & 32 & 10 & 44 & 39 & 24 & 16 \\
\hline & Species & 38 & 10 & 59 & 56 & 28 & 16 \\
\hline & Density & 0.19 & 0.23 & 0.52 & 0.60 & - & - \\
\hline \multirow[t]{4}{*}{ Xibei village } & Families & 13 & 4 & 25 & 22 & 12 & 14 \\
\hline & Genera & 17 & 4 & 37 & 38 & 16 & 18 \\
\hline & Species & 22 & 4 & 55 & 58 & 19 & 19 \\
\hline & Density & 0.14 & 0.23 & 0.39 & 0.49 & - & - \\
\hline \multirow[t]{4}{*}{ Datang village } & Families & 11 & 12 & 39 & 33 & 21 & 13 \\
\hline & Genera & 13 & 18 & 67 & 63 & 33 & 17 \\
\hline & Species & 13 & 19 & 99 & 84 & 39 & 20 \\
\hline & Density & 0.05 & 0.26 & 1.16 & 1.32 & - & - \\
\hline
\end{tabular}

However, NCPFs had only four species in the tree layer (Table 2). The shrub layer in CPFs was composed of Theaceae, Aquifoliaceae and Ericaceae, and the dominant species were Cinnamomum austrosinense and Antidesma japonicum (Table S1). In the NCPFs, the main families were Lauraceae, Theaceae, and Ericaceae with the dominant species being Adinandra millettii and Vaccinium carlesii (Table S1).

Cemetery forests in Datang village had relatively fewer species in the tree layers compared with those in the NCPFs. The most common families in the tree layer were Fagaceae and Lauraceae in both CPFs and NCPFs. The dominant species in CPFs were Cinnamomum camphora and Pinus massoniana, while the dominant species in NCPFs were Cunninghamia lanceolata and Camellia oleifera. The shrub and herb layers of CPFs had more species than those of NCPFs. In the shrub layer, the dominant families were Verbenaceae in CPFs and Euphorbiaceae in NCPFs respectively.

\section{Height, individual distribution (average frequency distribution of $\mathrm{DBH}$ ) and density}

Trees in CPFs were higher (averagely $10.8 \mathrm{~m}$ ) and had a bigger DBH (averagely $16.4 \mathrm{~cm}$ ) than those in NCPFs (height: $9.2 \mathrm{~m}$; DBH: $10.1 \mathrm{~cm}$ ) (Figs. 2, 3). For community forests and ancestral temple forests, $89.3 \%$ of the trees had a DBH ranged from 3 to $30 \mathrm{~cm}$. Trees with a DBH greater than $50 \mathrm{~cm}$ represented $4.4 \%$ of the whole tree layer, the largest being an individual Castanopsis carlesii with a DBH of $171.4 \mathrm{~cm}$. For the cemetery forests, only $25.7 \%$ of the trees had a DBH between 3 and $30 \mathrm{~cm}$, the rest were very large trees with 


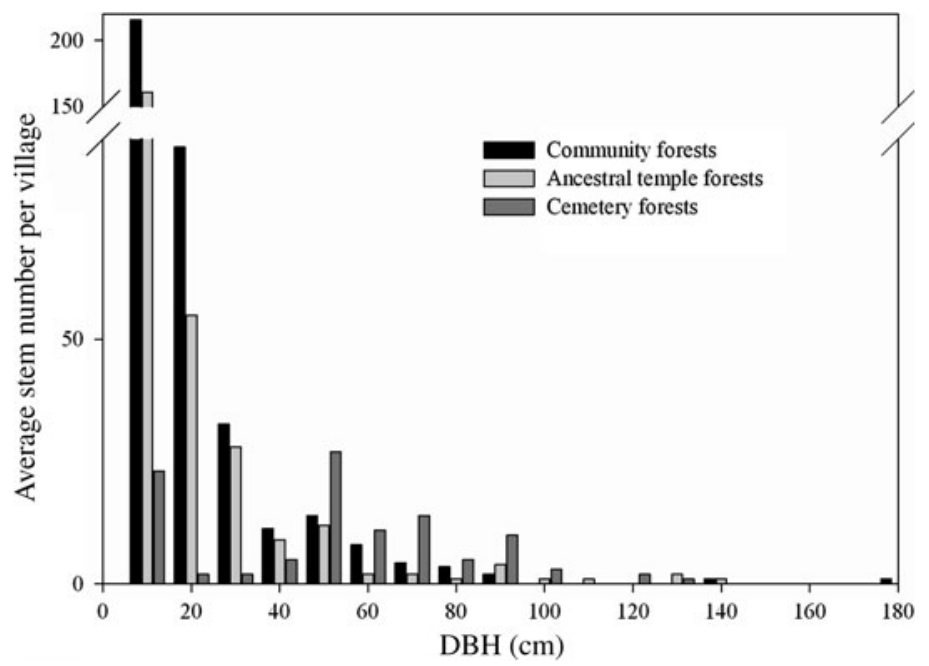

Fig. 3 Average distribution of frequency of $\mathrm{DBH}(\mathrm{cm})$ in three types of CPFs

$43.8 \%$ of them having a DBH greater than $50 \mathrm{~cm}$. The largest tree in cemetery forests was a Pistacia chinensis with a DBH of $120.0 \mathrm{~cm}$. In NCPFs, the distribution of DBH from 3 to $30 \mathrm{~cm}$ was $98.4 \%$, with only $0.1 \%$ greater than $50 \mathrm{~cm}$. The stand density in CPFs was relatively low compared with the NCPFs (Table 2).

Alpha and beta diversity in CPFs and NCPFs

\section{Alpha diversity}

The Simpson index, Shannon-Wiener index and Pielou evenness index of the tree layer in CPFs were higher than those in NCPFs with a significant difference for all sites except for the cemetery forests in Datang village (Table 3). Most of the indices for the shrub layer and herb layer in CPFs were higher than those in NCPFs, and 20 out of 45 index values showed a significant difference (Table 3). The only exceptions to this overall pattern were the index values for the Xibei and Longtan herb layer, which were slightly (though not significantly) lower in CPFs.

\section{Beta diversity}

CPFs harboured most of the species in the local area, and $80.0 \%$ of the species found in three layers around five villages presented in the CFPs. There was low similarity (Bray-Curtis index) between the tree layers of CPFs and NCPFs. Compared with natural NCPFs, the planted NCPFs had less species similarity with CPFs (Table 4). Particularly for the tree layer, the differences between CPFs and NCPFs were substantial where CPFs harboured $85.4 \%$ of all tree species found in total and the species only presented in CPFs were on average $52.4 \%$ in each village (Fig. 4). The similarity of the shrub layer was relatively high (Table 4), and the ratio of species presented in each type of forest was almost the same. The proportion of common species was $57.6 \%$ of all species found and from 32.2 to $67.4 \%$ in the shrub layer of each village (Fig. 4). Of the species in the shrub 
Table 3 Difference in biodiversity indices of CPF and NCPFs

\begin{tabular}{|c|c|c|c|c|c|c|c|c|c|c|c|}
\hline \multirow[t]{2}{*}{ Layer } & \multirow[t]{2}{*}{ Index } & \multicolumn{2}{|c|}{ Longtan } & \multicolumn{2}{|c|}{ Fenshui } & \multicolumn{2}{|c|}{ Jiangwan } & \multicolumn{2}{|l|}{ Xibei } & \multicolumn{2}{|c|}{ Datang } \\
\hline & & CPFs & NCPFs & CPFs & NCPFs & CPFs & NCPFs & CPFs & NCPFs & CPFs & NCPFs \\
\hline \multirow{3}{*}{$\begin{array}{l}\text { Tree } \\
\text { layer }\end{array}$} & Shannon & 2.63 & $1.58 *$ & 3.32 & $2.82 *$ & 2.34 & $0.60 *$ & 2.41 & $0.59 *$ & 1.95 & 1.95 \\
\hline & Simpson & 0.87 & $0.68 *$ & 0.95 & $0.91 *$ & 0.83 & $0.31 *$ & 0.88 & $0.35^{*}$ & 0.82 & 0.81 \\
\hline & Pielou & 0.46 & $0.24 *$ & 0.56 & 0.46 & 0.39 & $0.10^{*}$ & 0.43 & $0.10 *$ & 0.46 & $0.32 *$ \\
\hline \multirow{3}{*}{$\begin{array}{l}\text { Shrub } \\
\text { layer }\end{array}$} & Shannon & 3.76 & $3.69 *$ & 3.52 & 2.36 & 2.88 & $2.67 *$ & 3.19 & 2.50 & 3.46 & 3.29 \\
\hline & Simpson & 0.96 & 0.96 & 0.96 & 0.70 & 0.91 & $0.87 *$ & 0.94 & 0.93 & 0.93 & 0.93 \\
\hline & Pielou & 0.58 & 0.58 & 0.46 & 0.29 & 0.41 & $0.38 *$ & 0.48 & 0.36 & 0.47 & 0.43 \\
\hline \multirow{3}{*}{$\begin{array}{l}\text { Herb } \\
\text { layer }\end{array}$} & Shannon & 2.77 & 2.95 & 2.30 & 2.09 & 3.04 & $2.23 *$ & 2.27 & 2.49 & 3.35 & $2.61 *$ \\
\hline & Simpson & 0.91 & 0.95 & 0.88 & 0.83 & 0.95 & $0.87 *$ & 0.85 & 0.90 & 0.95 & 0.89 \\
\hline & Pielou & 0.64 & 0.63 & 0.54 & 0.54 & 0.67 & $0.52 *$ & 0.54 & 0.55 & 0.76 & 0.64 \\
\hline
\end{tabular}

* Significant difference $(P<0.05)$ between CPFs and NCPFs

Table 4 Bray-Curtis index between CPFs and NCPFs

\begin{tabular}{lllccc}
\hline Layer & Longtan village & Fenshui village & Jiangwan village & Xibei village & Datang village \\
\hline Tree layer & $11.2 \%$ & $31.4 \%$ & $1.3 \%$ & $8.1 \%$ & $12.8 \%$ \\
Shrub layer & $24.6 \%$ & $32.0 \%$ & $25.8 \%$ & $16.0 \%$ & $25.8 \%$ \\
Herb layer & $19.3 \%$ & $50.7 \%$ & $14.5 \%$ & $30.5 \%$ & $14.5 \%$ \\
\hline
\end{tabular}

layer of NCPFs, $37.4 \%$ were found in the tree layer of CPFs, while only $23.9 \%$ were found in the tree layer of NCPFs. The similarity index of the herb layer showed high variation, with on average $23.3 \%$ common species between CPFs and NCPFs (Fig. 4).

Protected species

CPFs had significant contribution to protect endangered species for the local area. 17 protected species were found in the CPFs in China Species Red List and IUCN Red List (Table 5), and eight in NCPFs (Walter and Gillett 1998; Wang and Xie 2004). Six species in the CPFs were critically endangered (CR), two species were endangered (EN), eight were vulnerable (VU), and one was Lower Endangered (LE) in CPFs. Furthermore, CPFs included seven protected species which occurred in NCPFs, with only one species near threatened-Liparis nervosa occurring in NCPFs.

\section{Discussion and Conclusions}

The results of our research imply that CPFs can play a significant role in biodiversity conservation. Biodiversity in the CPFs was higher than that in NCPFs. Similar findings were found in other research, such as for fengshui forests in Pearl Delta (Hu et al. 2011), traditional forests in Southwest China (Liu et al. 2002; Mo et al. 2011) and sacred forests in Mozambique (Virtanen 2002). Of the three types of CPFs, community forests and ancestral temple forests sheltered large proportions of local biodiversity. About half of the indices 


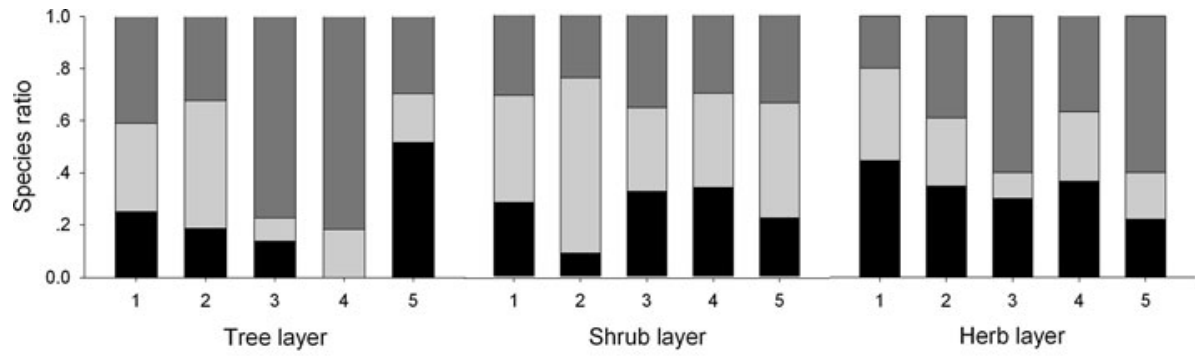

ratio of species only exist in NCPFs

ratio of common species in CPFs and NCPFs

ratio of species only exist in CPFs

Fig. 4 Unique species and common species ratio of CPFs and NCPFs ( 1 Longtan village, 2 Fenshui village, 3 Jiangwang village, 4 Xibei village, 5 Datang village)

Table 5 State protected species in CPFs and NCPFs

\begin{tabular}{|c|c|c|c|c|c|c|}
\hline ID & Families & Latin name & $\begin{array}{l}\text { Protected } \\
\text { level }\end{array}$ & $\begin{array}{l}\text { Evaluation } \\
\text { grade }\end{array}$ & CPFs & NCPFs \\
\hline 1 & Leguminpsae & Pterocarpus indicus & II & $\mathrm{CR}$ & $\sqrt{ }$ & \\
\hline 2 & Rubiaceae & Mussaenda shikokiana & & $\mathrm{CR}$ & $\sqrt{ }$ & \\
\hline 3 & Araliaceae & Schefflera octophylla & & $\mathrm{CR}$ & $\sqrt{ }$ & \\
\hline 4 & Daphniphyllaceae & Daphniphyllum oldhami & & $\mathrm{CR}$ & $\sqrt{ }$ & $\sqrt{ }$ \\
\hline 5 & Lauraceae & Machilus pingii & II & $\mathrm{CR}$ & $\sqrt{ }$ & \\
\hline 6 & Euphorbiaceae & Sapium discolor & & $\mathrm{CR}$ & $\sqrt{ }$ & $\sqrt{ }$ \\
\hline 7 & Taxaceae & Taxus chinensis var. mairei & I & EN & $\sqrt{ }$ & \\
\hline 8 & Araliaceae & Aralia chinensis & & EN & $\sqrt{ }$ & $\sqrt{ }$ \\
\hline 9 & Lauraceae & Cinnamomum camphora & II & VU & $\sqrt{ }$ & $\sqrt{ }$ \\
\hline 10 & Leguminpsae & Ormosia henryi & II & VU & $\sqrt{ }$ & $\sqrt{ }$ \\
\hline 11 & Orchidaceae & Cymbidium goeringii & I & VU & $\sqrt{ }$ & \\
\hline 12 & Theaceae & Camellia japonica & II & VU & $\sqrt{ }$ & \\
\hline 13 & Araliaceae & Dendropanax dentigerus & & VU & $\sqrt{ }$ & $\sqrt{ }$ \\
\hline 14 & Staphyleaceae & Euscaphis japonica & & VU & $\sqrt{ }$ & \\
\hline 15 & Magnoliaceae & Magnolia denudata & & VU & $\sqrt{ }$ & \\
\hline 16 & Pinaceae & Tsuga longibracteata & & VU & $\sqrt{ }$ & \\
\hline 17 & Orchidaceae & Liparis nervosa & & NT & & $\sqrt{ }$ \\
\hline 18 & Dicksoniaceae & Cibotium barometz. & II & $\mathrm{LC}$ & $\sqrt{ }$ & $\sqrt{ }$ \\
\hline
\end{tabular}

tested were significantly higher for the CPFs than for the NCPFs. Cemetery forests, while they had fewer species in the tree layer compared with NCPFs within the same local area, were important for biodiversity protection as they harboured very old trees with a large $\mathrm{DBH}$, a structural feature absent from other forest types studied. Moreover, the composition of the dominant tree community provided clues for the effectiveness of CPFs in conserving biodiversity. CPFs had experienced an extended period of succession and regeneration, which had resulted in a stable forest structure with a clear stratification of layers. The attributes of the forest communities found in CPFs are comparable to 
well-developed evergreen broad-leaved forests in the region, and the dominant families of $\mathrm{CPFs}$ recorded in this study are congruent with reports from main types of evergreen broad-leaved forests in the eastern part of middle subtropical China (He et al. 1998), from Wuyi Mountain National Natural Reserve in Fujian Province (Lan 2003; Kong and Li 2011), and from Lu Mountain National Natural Reserve in Jiangxi Province (Luo and Li 1996). These similarities suggest that CPFs can be considered as patches of well-developed broad-leaved forest in Southeast China.

In addition, the CPFs not only protect local biodiversity, but also conserve indigenous species and preserve the physiognomy of the community. Most of the dominant species in the tree layer were indigenous broad-leaved species in the late stage of succession. In NCPFs, the dominant species were easily cultivated and form conifer dominated mixed broadleaf-conifer forests. The dominant tree species in CPF patches could be valuable for the restoration of forests, and may also provide a standard for evaluating its effectiveness, in line with the suggestion of Ren et al. (2007). For example, Schima superb, Cinnamomum austrosinense, Cyclobalanopsis glauca are key species for restoration (Peng 1996). Moreover, since $85.4 \%$ of the local trees species identified were found in CPFs, these forests may act as seed (species) pools to neighboring forests and areas.

With regard to protection of endangered species, 17 species were found in CPFs that were listed as endangered species in IUCN Red List and China Species Red List. According to recent investigations on the biodiversity of Fujian (Fujian Provincial Academy of Environmental Science, 2011) and unpublished results of biodiversity evaluation research in Jiangxi Province by Environmental Protection Department, there are 100 endangered plant species in the four counties where the five villages are located. This means that the investigated CPFs harbour $17 \%$ of their counties' threatened species, even when these CPFs are less than $0.02 \%$ of the total forests area of the four counties.

The relatively high levels of biodiversity in CPFs were plausibly caused by the differences in management and resource use between CPFs and NCPFs. The historical resource use in these CPFs was and still is limited to collecting non-timber products, including dead wood and leaves for fuel, fruits and mushrooms for food, and Chinese herbs for medicine. However, cutting economically valuable trees and shrubs was permitted in the NCPFs. Examples of trees that were cut in NCPFs were Cunninghamia lanceolata in Xibei village and Camellia oleifera in Datang village. Although China has been crafting a Western-style rule of law since the late 1970s ( $\mathrm{Li} 2010$ ), traditional beliefs and village rules or regulations are still important for restraining the behavior of residents and the way they managed the forests (Yuan and Liu 2009). In the social survey of the same villages (Gao et al. unpublished), it was reported that anyone who destroyed CPFs would be punished under village rules and informal regulations, maintained by the village committee. For instance, the committee might kill an offender's family pig and distribute the meat to other villagers. Other punishments mentioned were insisting on self-criticism in front of villagers, replanting trees, or paying a fine. Such findings are in line with other research demonstrating that local communities can be actively engaged in maintaining biodiversity in the forest landscape for future populations and fulfilling livelihood needs (Wiersum 2003).

According to the social survey of CPFs, most villagers considered forests as natural protective screens to defend villages from disaster and ensure safety and well-being. In their perception, CPFs provided not only clean air and water, and improved the local climate, but also cultural value to the community, related to their beauty, cultural heritage, and spiritual meaning. Also recreation and tourism were mentioned as an important benefit, particularly in the case of the ancestral temple forest. 
Taken together, our findings suggest that there are good reasons for seriously investigating the potential roles of local motivations and traditional customs and village rules in protecting biodiversity in Southeast China. The positive attitudes towards CPFs and the informal rules to protect them are still effective today, as is demonstrated by our biodiversity investigation and social survey.

Without support from government and NGOs there is a serious risk that the effectiveness of local rules and the significance of CPFs for biodiversity conservation will diminish in the years to come. Governments in Fujian and Jiangxi Provinces have tried to support to establish small protected area protecting small ecosystems with special ecological values and areas of cultural importance for local communities, and some of these small protected areas were based on CPFs (State Environmental Protection Administration 2000). Furthermore, local preservation of CPFs should not be seen as an alternative that stands apart from government regulation, but rather as a complementary strategy within a supportive regulatory framework. The merits of informal regulations need to be recognized, encouraged, and integrated into existing policy frameworks of government. Additionally, both provinces surveyed have undergone forest tenure reform. In the reform, collectives have the option of reallocating forest rights to individual households but they can also keep patches of forest as collectively owned (Xu et al. 2010). The CPFs investigated were designated by the village committees for collective usage and ceremonial activities, while the other local forests, including the NCPFs investigated, were allocated to households. The community owned status of CPFs and the legitimate application of local rules would need acknowledgement and support from government. It is also plausible that as a large network of forest patches, CPFs can preserve a sizeable portion of the biodiversity in local area and a region.

Acknowledgments We extend thanks to the anonymous reviewers and chief editor for their great valuable comments to this manuscript. We thank Professor Xianghai Kong in Longyan College, Ceming Tan, curator of Jiujiang Herbarium and Yuanhua Hong, station master of Wuyuan forestry, for great help in field research and identifying species. We would also like to thank Weihuan Wu, Wenchao Zhang, Yuanzhi Li, students of Xiamen University, for assistance in vegetation investigation.

\section{References}

Achard F, Eva HD, Stibig HJ, Mayaux P, Gallego J, Richards T, Malingreau JP (2002) Determination of deforestation rates of the world's humid tropical forests. Science 297(5583):999-1002

Ai HS, Zhou H (2003) Deity mountain forest and its function in natural reservation in Gaoligong mountain of Yunnan province. Chin J Ecol 22(2):92-96

Berkes F, Davidson IJH (2006) Biodiversity, traditional management systems, and cultural landscapes: examples from the boreal forest of Canada. Int Soc Sci J 58(187):35-47

Bhagwat SA, Rutte C (2006) Sacred groves: potential for biodiversity management. Front Ecol Environ 4(10):519-524

Byers BA, Cunliffe RN, Hudak AT (2001) Linking the conservation of culture and nature: a case study of sacred forests in Zimbabwe. Hum Ecol 29(2):187-218

Ceperley N, Montagnini F, Natta A (2010) Significance of sacred sites for riparian forest conservation in Central Benin. Bois et Forêts des Tropiques 303(1):5-23

Chun YW, Tak KI (2009) Songgye, a traditional knowledge system for sustainable forest management in Choson Dynasty of Korea. For Ecol Manage 257(10):2022-2026

Cui Y, Zhang GG, Chen DW, He TP, Pang J, Huang FY (2008) Species diversity and conservation of Feng Shui wood in Napo county. J Agric Biol Sci 27:53-56

Fabricius C (2004) Rights, resources and rural development: community-based natural resource management in Southern Africa. Earthscan, London 
Fang JM, Sun H, Zhang YZ (2007) The significance of the traditional culture of Sichuan Tibetan region to biodiversity protection. World Sci-Tech R \& D 29(4):66-71

Garnett ST, Sayer J, Du Toit J (2007) Improving the effectiveness of interventions to balance conservation and development: a conceptual framework. Ecol Soc 12(1):2

Guan CY (2002) Investigation on geomantic forest in ancient China. Agric Archaeol 3:239-243

He JS, Chen WL, Li LH (1998) Community diversity of the main types of the evergreen broad-leaved forest in the eastern part of the middle subtropical China. Acta Phytoecologica Sinica 22(4):303-311

Hu L, Li Z, Liao W, Fan Q (2011) Values of village fengshui forest patches in biodiversity conservation in the Pearl River Delta, China. Biol Conserv 144(5):1553-1559

Infield M (2001) Cultural values: a forgotten strategy for building community support for protected areas in Africa. Conserv Biol 15(3):800-802

Jamir SA, Pandey H (2003) Vascular plant diversity in the sacred groves of Jaintia Hills in northeast India. Biodivers Conserv 12(7):1497-1510

Jim CY (2003) Conservation of soils in culturally protected woodlands in rural Hong Kong. For Ecol Manage 175(1-3):339-353

Kong XH, Li ZJ (2011) The community characteristic of evergreen broad-leaved forest in Meihuashan National Nature Reserve of Fujian. J Xiamen Univ (Nat Sci) 50(3):645-650

Lan SR (2003) Plant species diversity in Wuyishan National Nature Reserve. Scientia Silvae Sinicae 39(1):36-43

Legendre P, Borcard D, Peres-Neto PR (2005) Analyzing beta diversity: partitioning the spatial variation of community composition data. Ecol Monogr 75(4):435-450

Li C (2010) China's Communist Party-State: the structure and dynamics of power. In: Joseph W (ed) Politics in China: an introduction. Oxford University Press, London

Liao Y, Chen C, Chen H, Zhang J, Wu Z, Liu L (2008) The community characters and plant diversity of fengshui woods in Liantang country, Guangzhou. Ecol Environ 17:812-817

Liu HM, Xu ZF, Xu YK, Wang JX (2002) Practice of conserving plant diversity through traditional beliefs: a case study in Xishuangbanna, southwest China. Biodivers Conserv 11(4):705-713

Long CL, Zhang FY, Pei SJ, Chen SY (1999) Impacts of traditional culture of Yi nationality upon biodiversity in Zixishan Mountain area, Yunnan. Biodiversity Sci 7(3):245-249

Loreau M, Naeem S, Inchausti P, Bengtsson J, Grime JP, Hector A, Hooper DU, Huston MA, Raffaelli D, Schmid B (2001) Biodiversity and ecosystem functioning: current knowledge and future challenges. Science 294(5543):804-808

Lü H, Liu S, Zhu J, Ye Y, Chen H, Mo L (2008) Effects of human disturbance on understory woody species composition and diversity in fengshui forests. Acta Entomologica Sinica 51(5):1017-1098

Luo GT, Li JX (1996) Analysis on community characteristic of broad-leaved forest on Lushan mountain. Natur Sci J Harbin Norm Univ 4(12):95-102

Luo Y, Liu J, Zhang D (2009) Role of traditional beliefs of Baima Tibetans in biodiversity conservation in China. For Ecol Manage 257(10):1995-2001

Magurran AE (1988) Ecological diversity and its measurement. Princeton university press, Princeton

Magurran AE (2005) Measuring biological diversity. Blackwell, London

Mgumia F, Oba G (2003) Potential role of sacred groves in biodiversity conservation in Tanzania. Environ Conserv 30(3):259-265

Mo XX, Zhu H, Zhang YJ, Ferry Slik JW, Liu JX (2011) Traditional forest management has limited impact on plant diversity and composition in a tropical seasonal rainforest in SW China. Biol Conserv 144(6):1832-1840

Page NV, Qureshi Q, Rawat GS, Kushalappa CG (2010) Plant diversity in sacred forest fragments of Western Ghats: a comparative study of four life forms. Plant Ecol 206(2):237-250

Peng SL (1996) Restoration ecology theories and their application in low subtropics. J Trop Subtrop Botany 4(3):36-44

Pimm SL, Russell GJ, Gittleman JL, Brooks TM (1995) The future of biodiversity. Science 269(5222):347-350

Ren H, Li ZA, Shen WJ, Yu ZY, Peng SL, Liao CH, Ding MM, Wu JG (2007) Changes in biodiversity and ecosystem function during the restoration of a tropical forest in south China. Sci China, Ser C Life Sci 50(2):277-284

Salick J, Amend A, Anderson D, Hoffmeister K, Gunn B, Zhendong F (2007) Tibetan sacred sites conserve old growth trees and cover in the eastern Himalayas. Biodivers Conserv 16(3):693-706

Shannon CE, Weaver W (1949) The mathematical theory of communication. University of Illinois Press, New York

Simpson EH (1949) Measurement of diversity. Nature 163:688 
Soury A, van Koppen K, Tchibozo MS, Cotonou B (2007) Sacred forests: a sustainable conservation strategy? The case of sacred forests in the Ouémé valley, Benin. Wageningen University, Wageningen

State Environmental Protection Administration (2000) National nature reserve development planning. Academy Press, Beijing

Virtanen P (2002) The role of customary institutions in the conservation of biodiversity: sacred forests in Mozambique. Environ Values 11(2):227-241

Wadley RL, Colfer CJP (2004) Sacred forest, hunting, and conservation in West Kalimantan, Indonesia. Hum Ecol 32(3):313-338

Walter KS, Gillett HJ (1998) 1997 IUCN red list of threatened plants. World Conservation Union, Switzerland

Wang S, Xie Y (2004) China species red list. Higher Education Press, Beijing

Wassie A, Sterck FJ, Bongers F (2010) Species and structural diversity of church forests in a fragmented Ethiopian Highland landscape. J Veg Sci 21(5):938-948

Wiersum KF (2003) Use and conservation of biodiversity in East African forested landscapes. Utrecht University, Netherlands

Xu ZF (2008) Preliminary comparison on traditional knowledge of medicinal plants used by Dai Xishuangbanna China and Khmer Cambodia. Acta Metall Sin 30(03):371-377

Xu J, Ma ET, Tashi D, Fu Y, Lu Z, Melick D (2005) Integrating sacred knowledge for conservation: cultures and landscapes in southwest China. Ecol Soc 10(2):7

Xu J, Lebel L, Sturgeon J (2009) Functional links between biodiversity, livelihoods, and culture in a Hani swidden landscape in southwest China. Ecol Soc 14(2):20

$\mathrm{Xu} \mathrm{J}$, White A, Lele UJ (2010) China's forest tenure reforms: impacts and implications for choice, conservation, and climate change. Rights and Resources Initiative, Washington

Yang Y, Zhao D (2004) Protective significance of deity mountain forest culture to ecological resourcesfocused in the ethnical minorities in Southwest region. J Central Univ Nationalities (Natur Sci Edition) 13(4):364-368

Yuan J, Liu J (2009) Fengshui forest management by the Buyi ethnic minority in China. For Ecol Manage 257(10):2002-2009

Zhang J (2004) Quantitative ecology. Science Press, Beijing

Zhong ZQ, Boris DC (2007) Fengshui-a systematic research of vernacular sustainable development. In: Ancient China and its lessons for the future: proceedings, 7th annual general meeting, UK-Chinese Association of Resources and Environment (UK CARE), Greenwich, 15 Sept 2007

Zou L, Xie ZQ, Kun OX (2005) Significance of Tibetan sacred hills in nature conservation of Shangri-La Gorge, Yunnan. Biodiversity Sci 13(1):51-57 